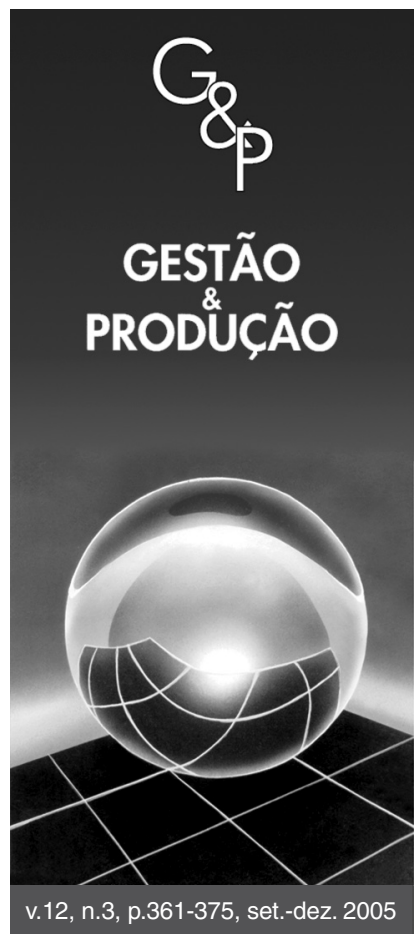

\title{
COMPARAÇÃO ENTRE AS TENDÊNCIAS E ESTRATÉGIAS DA INDÚSTRIA AUTOMOTIVA NO BRASIL E NA EUROPA
}

\author{
Luiz Felipe Scavarda \\ Tiago Peixoto Wermelinger Barbosa \\ Sílvio Hamacher
}

Departamento de Engenharia Industrial, Pontifícia Universidade Católica do Rio de Janeiro, PUC-Rio, Rua Marquês de São Vicente, 225, CEP 22453-900, RJ, e-mail: Ifscava@ind.puc-rio.br, tiagopwb @yahoo.com.br, hamacher@ind.puc-rio.br

Resumo

A indústria automotiva está passando por transformações que vêm provocando a diversificação e segmentação do mercado, a redução do ciclo de vida de modelos de veículos e a oferta de variedades de atributos desses modelos para os clientes. Este artigo tem por objetivos analisar essas tendências e avaliar as principais estratégias desenvolvidas e implementadas pelas montadoras de veículos nos mercados brasileiro e europeu, para fazer face a estas tendências. Os resultados obtidos no Brasil pelos autores deste artigo foram analisados tendo como base a metodologia científica adotada em uma pesquisa similar desenvolvida na Europa. Os resultados mostram como as estratégias de plataformas, de configuração tardia e de pacotes de opcionais estão sendo implementadas pelas montadoras, permitindo uma comparação entre os dois mercados examinados.

Palavras-chave: indústria automotiva, variedade de atributos, plataformas, modularização, configuração tardia.

\section{Introdução}

No passado, as primeiras montadoras de veículos de série ofereciam ao mercado um modelo único, com poucas variedades de atributos e com um longo ciclo de vida. Este foi o caso da Ford, com o seu Modelo T, e o da Volkswagen (VW), com o Fusca.

Atualmente, as montadoras de veículos encontram um cenário bem diferente do mercado americano do início do século passado e do europeu dos anos 40 e 50 . $\mathrm{O}$ mercado consumidor ficou mais exigente e seletivo, a indústria automotiva passou por um período de grandes aquisições e fusões e as montadoras passaram a atuar em quase todos os principais segmentos de mercado. Para fazer face a estas questões, as montadoras têm buscado diversificar e segmentar os modelos de veículos e seus estilos de carrocerias, reduzir o ciclo de vida destes modelos e oferecer uma grande variedade de combinações de atributos aos clientes.
Neste contexto, o presente artigo tem por objetivos: 1) analisar as tendências oriundas deste novo cenário, tanto no mercado europeu quanto no mercado brasileiro; e 2) avaliar as principais estratégias resultantes que vêm sendo desenvolvidas e implementadas pelas montadoras nestes dois mercados.

O presente artigo se insere no projeto de pesquisa europeu intitulado "Intelligent Logistics for Innovative Product Technologies" (ILIPT). Este projeto busca repensar a atual gestão da cadeia de suprimentos da indústria automotiva européia, de forma a reduzir a apenas cinco dias úteis o tempo transcorrido entre a solicitação de um veículo personalizado e a sua entrega ao cliente final.

$\mathrm{O}$ artigo está dividido em cinco seções, incluindo esta introdutória. A segunda seção apresenta a metodologia científica adotada no artigo. A terceira seção introduz e analisa as tendências na indústria automotiva, enquanto 
que a quarta seção tem como enfoque as estratégias adotadas pelas montadoras diante destas tendências. A terceira e a quarta seções abordam e comparam os mercados europeu e brasileiro. A última seção apresenta as principais conclusões obtidas pelos autores deste artigo.

\section{Metodologia}

A primeira parte da pesquisa que resultou neste artigo teve como base uma revisão bibliográfica sobre o tema de interesse. Foram adicionadas a esta revisão informações obtidas em um workshop com pesquisadores europeus do projeto ILIPT, que estiveram envolvidos com o levantamento das tendências e das estratégias adotadas pela indústria automobilística para o mercado europeu. Também foram conduzidas entrevistas com quatro gerentes de duas grandes montadoras atuantes no Brasil, para adequar a pesquisa à realidade brasileira. Essas entrevistas abordaram as tendências e estratégias da indústria para o mercado brasileiro e, particularmente, a adoção de plataformas no Brasil e o tempo de ciclo de vida dos modelos de veículos fabricados no Brasil.

A metodologia utilizada para coletar dados de campo referentes a variações dos modelos de veículos oferecidos ao mercado brasileiro contou, inicialmente, com fontes secundárias de informação obtidas em consultas a sites de todas as 11 montadoras presentes no Brasil que produzem veículos de passeio, em prospectos (folders) sobre os modelos de veículos disponíveis nas concessionárias e em revistas e sites especializados na indústria automotiva. Essas informações foram, posteriormente, complementadas e confrontadas às informações obtidas em fontes primárias por meio de uma pesquisa de campo, que incluiu entrevistas semi-estruturadas com gerentes comerciais de concessionárias autorizadas de cada uma das montadoras que produzem veículos de passeio no Brasil. Essas entrevistas foram realizadas na região metropolitana do Rio de Janeiro em maio de 2005. A amostra analisada cobriu todos os modelos de veículos produzidos na região do Mercosul, classificados como automóveis de passageiros e de uso misto pela ANFAVEA (Associação Nacional dos Fabricantes de Veículos Automotores) e que estavam entre os 50 veículos mais vendidos no mercado brasileiro em 2004. A amostra incluiu também os automóveis de passeio Fiat Marea e o Renault Mégane, que não estavam listados entre os 50 mais vendidos, mas que possuem vendas significativas na Europa, bem como os comerciais leves originados de automóveis, como o Ford EcoSport, Ford Courier, General Motors (GM) Montana, Fiat Strada e VW Saveiro. Os demais comerciais leves (entre eles Ford Ranger, GM S10 e GM Blazer) e os comerciais pesados (caminhões e ônibus) não fizeram parte do escopo desta pesquisa. A amostra analisada correspondeu a, aproximadamente, $95 \%$ do mercado nacional de automóveis e comerciais leves do ano de
2004. Os dados de vendas e de produção brasileiros foram obtidos junto aos Anuários da ANFAVEA.

Informações específicas sobre o uso de pacotes de opcionais pelas montadoras GM e Ford foram obtidas a partir de entrevistas semi-estruturadas junto a dois gerentes comerciais de um grande distribuidor multimarcas, responsável por $25 \%$ das vendas de automóveis de passeio e comerciais leves novos, para as regiões do Rio de Janeiro e do Espírito Santo.

Os resultados obtidos no Brasil pelos autores deste artigo foram analisados tendo como base a metodologia científica adotada pelos pesquisadores europeus do ILIPT. Desta forma, os resultados das regiões puderam ser comparados. Informações mais específicas sobre a metodologia se encontram ao longo do texto, sempre que necessário.

\section{Tendências na indústria automotiva}

Esta seção tem por objetivo analisar as tendências na indústria automotiva que respondem ao cenário mercadológico enfrentado pelas montadoras de veículos, tanto para a realidade do mercado europeu, quanto para a do mercado brasileiro. As seguintes tendências serão analisadas: diversificação e segmentação do mercado automotivo; redução do tempo de ciclo de vida; e oferta da variedade de atributos dos modelos de veículos.

\subsection{Diversificação e segmentação do mer- cado automotivo}

Uma das principais evoluções ocorridas nas últimas décadas na indústria automotiva foi o crescimento do número de modelos oferecidos por montadora. Por exemplo, o grupo Volkswagen está levando adiante um plano que tem por objetivo competir em todos os segmentos do mercado automobilístico. Os recentes lançamentos dos modelos Touareg e Phaeton são exemplos dessa expansão da marca nos segmentos de utilitários esportivos e sedan de luxo, respectivamente (Carvalho, 2005).

A Figura 1 apresenta a evolução no número de modelos de veículos mais vendidos no Reino Unido entre 1960 e 2000. O número de modelos produzidos em média por cada montadora passou de 2, em 1960, para 8,6 modelos, em 2000. O desejo dos fabricantes de automóveis de ampliar a segmentação do mercado, assim como a pressão por produtos novos para manterem-se competitivos, é a principal razão desse fenômeno, de acordo com Holweg e Greenwood (2001a).

Esta tendência de proliferação de modelos por montadoras também é vista em outros mercados. A Figura 2 mostra a evolução do número de modelos produzidos e vendidos no Brasil pelas quatro montadoras veteranas*.

\footnotetext{
*. Os termos "veteranas" e "entrantes" foram empregados no Relatório Setorial “Automóveis” da FINEP(Consoni, 2004) para designar, respectivamente, as montadoras presentes no Brasil até 1990 (isto é, VW, Fiat, GM e Ford) e a partir desse ano (isto é, Renault, Peugeot/Citroen - PSA, Toyota, Daimler Chrysler, Honda).
} 
No Brasil, o número médio de modelos produzidos por cada uma das montadoras veteranas cresceu ao longo das décadas, chegando a quase 8 modelos por montadora em 2005. Aliado a essa expansão de modelos por montadora, também houve um aumento no número de estilos de carrocerias oferecidos (isto é, sedan, wagon, hatch, pick-up e conversível). A Tabela 1 apresenta a evolução do número de estilos de carrocerias produzidos pelas oito principais montadoras atuantes na Europa em termos de vendas (Fiat, Ford, GM, Nissan, PSA, Renault, Toyota e VW).

A Tabela 2 apresenta a evolução para o número de estilos de carrocerias produzidos no Brasil.

Na Tabela 1, nota-se que o número de estilos de carrocerias oferecidos pelas montadoras na Europa mais que

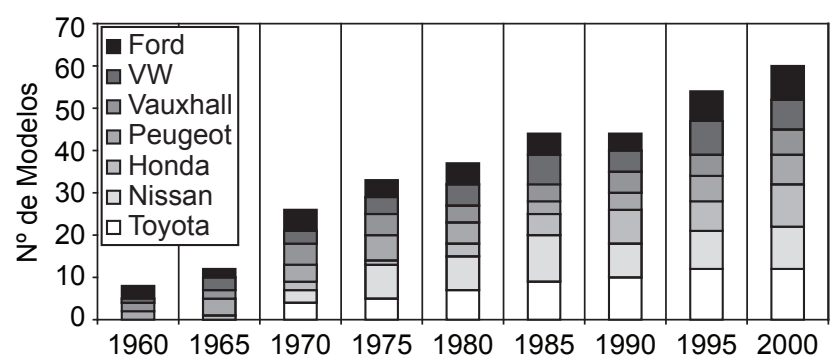

Figura 1. Número de modelos de veículos produzidos para o mercado do Reino Unido. Fonte: elaborado pelos autores, a partir de dados de Holweg e Greenwood (2001a).

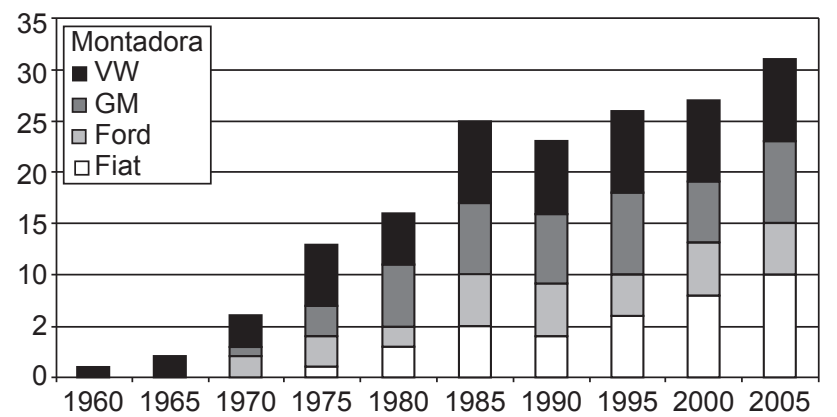

Figura 2. Número de modelos de veículos produzidos no Brasil. Fonte: elaborado pelos autores. dobrou entre 1990 e 2002 (razão 2,03), corroborando a tendência de diversificação e segmentação do mercado automotivo. No Brasil (Tabela 2), o crescimento entre 1980 e 2004 foi também muito expressivo. Além da estratégia de diversificação vista no mercado europeu, outra questão explica este crescimento diferenciado no Brasil: o início de produção local por parte de montadoras "novas entrantes" a partir de 1997. Assim, nota-se que o número de estilos de carrocerias das montadoras veteranas, praticamente, triplicou entre 1980 e 2004 (razão 2,93), mas quando os novos modelos das novas entrantes são considerados, o número total foi ampliado em 3,64 vezes.

\subsection{Tempo de ciclo de vida}

Aliada à questão do aumento do número de modelos de veículos e dos estilos de carrocerias, também aconteceu uma diminuição do ciclo de vida dos modelos de veículos. Holweg e Greenwoood (2001b) definem o ciclo de vida como o tempo entre a introdução do veículo no mercado até a sua substituição ou até uma significativa remodelagem. Re-estilizações em modelos, baseadas em simples trocas de faróis e/ou pára-choques, não são consideradas, por esses autores, como início de um novo ciclo de vida. A Figura 3 mostra o ciclo de vida dos 20 modelos de veículos mais vendidos no Reino Unido entre 1955 e 2000 . O eixo horizontal mostra o ano de introdução do modelo e o eixo vertical, a duração (em anos) do seu ciclo de vida.

Como pode ser observado na Figura 3, a média móvel de dez observações mostra ciclos de vida inferiores a 6 anos durante os anos 60, ciclos estes que passaram para cerca de 7 anos nos anos 70. Holweg e Greenwood (2001b) argumentam que a complexidade do veículo era relativamente pequena nos anos 60 , desta forma os ciclos de desenvolvimento eram curtos, em contraste com os modelos introduzidos posteriormente. Todavia, entre $1970 \mathrm{e}$ 2000, o ciclo de vida dos veículos decresceu para cerca de 5 anos. Os trabalhos de Holweg e Greenwood (2001b) e de J.D.Powers LMC (2000) prognosticam um ciclo de vida médio de 3,1 anos, na indústria automotiva européia para o ano de 2005.

A Figura 4 apresenta a evolução do ciclo de vida de 79 modelos de veículos produzidos no mercado bra-

Tabela 1. Número de estilos de carrocerias produzidos na Europa. Fonte: adaptado de Pil e Holweg (2004).

\begin{tabular}{lcccccccccc}
\hline & $\mathbf{1 9 9 0}$ & $\mathbf{1 9 9 5}$ & $\mathbf{1 9 9 6}$ & $\mathbf{1 9 9 7}$ & $\mathbf{1 9 9 8}$ & $\mathbf{1 9 9 9}$ & $\mathbf{2 0 0 0}$ & $\mathbf{2 0 0 1}$ & $\mathbf{2 0 0 2}$ & $\mathbf{2 0 0 2 / 1 9 9 0}$ \\
\hline $\mathrm{N}^{\mathbf{o}}$ Estilos & 88 & 137 & 139 & 148 & 157 & 159 & 167 & 175 & 179 & 2,03 \\
\hline
\end{tabular}

Tabela 2. Número de estilos de carrocerias produzidos no Brasil. Fonte: elaborado pelos autores.

\begin{tabular}{lccccccc}
\hline \multicolumn{1}{c}{$\mathbf{N}^{\mathbf{0}}$ Estilos } & $\mathbf{1 9 8 0}$ & $\mathbf{1 9 8 5}$ & $\mathbf{1 9 9 0}$ & $\mathbf{1 9 9 5}$ & $\mathbf{2 0 0 0}$ & $\mathbf{2 0 0 4}$ & $\mathbf{2 0 0 4 / 1 9 8 0}$ \\
\hline Todas as Montadoras & 14 & 31 & 26 & 32 & 36 & 51 & 3,64 \\
Veteranas & 14 & 31 & 26 & 32 & 31 & 41 & 2,93 \\
Novas entrantes & 0 & 0 & 0 & 0 & 5 & 10 & - \\
\hline
\end{tabular}




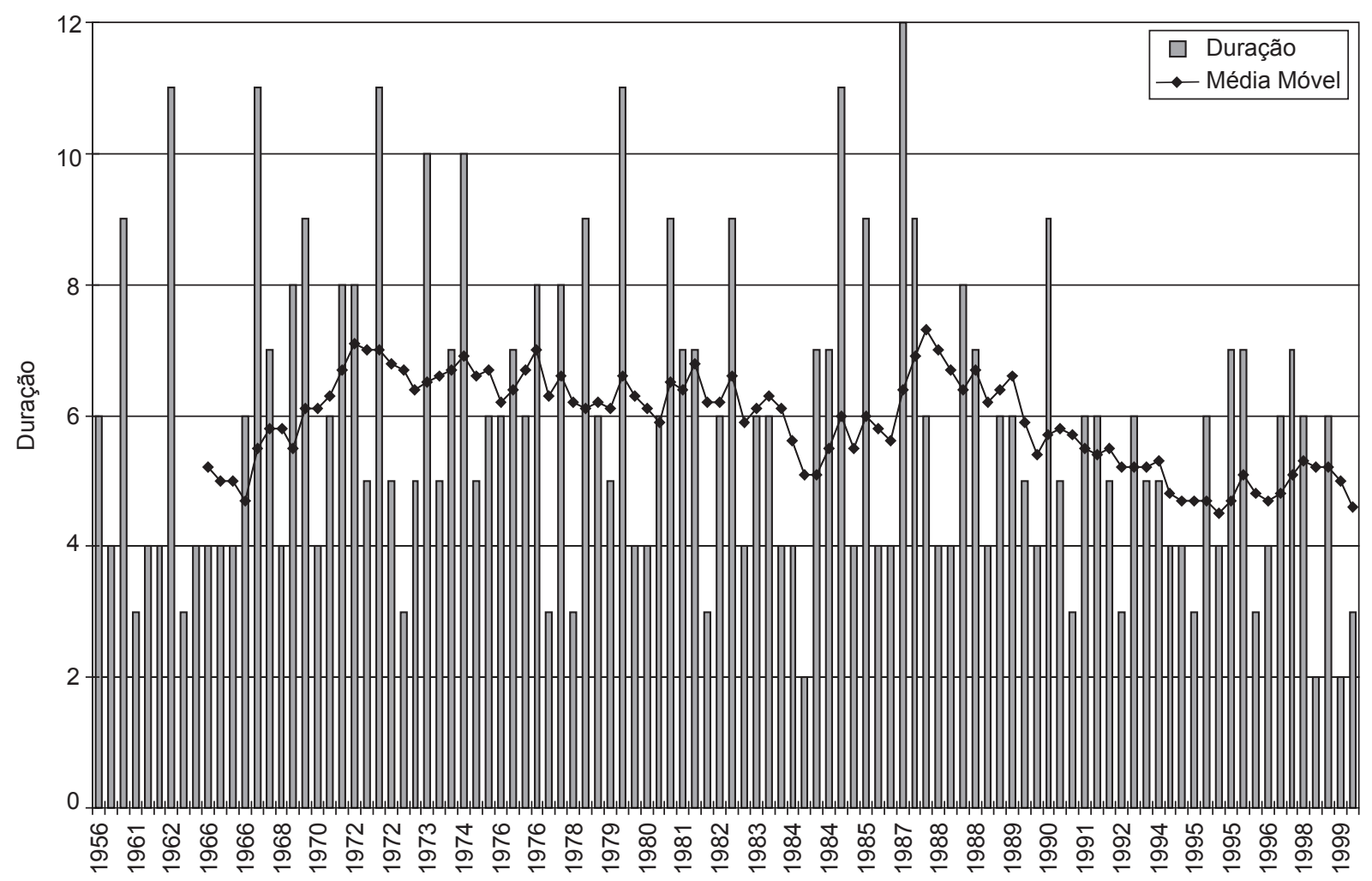

Figura 3. Ciclo de vida de modelos oferecidos ao mercado do Reino Unido. Fonte: elaborado pelos autores, a partir de dados de Holweg e Greenwood (2001b).

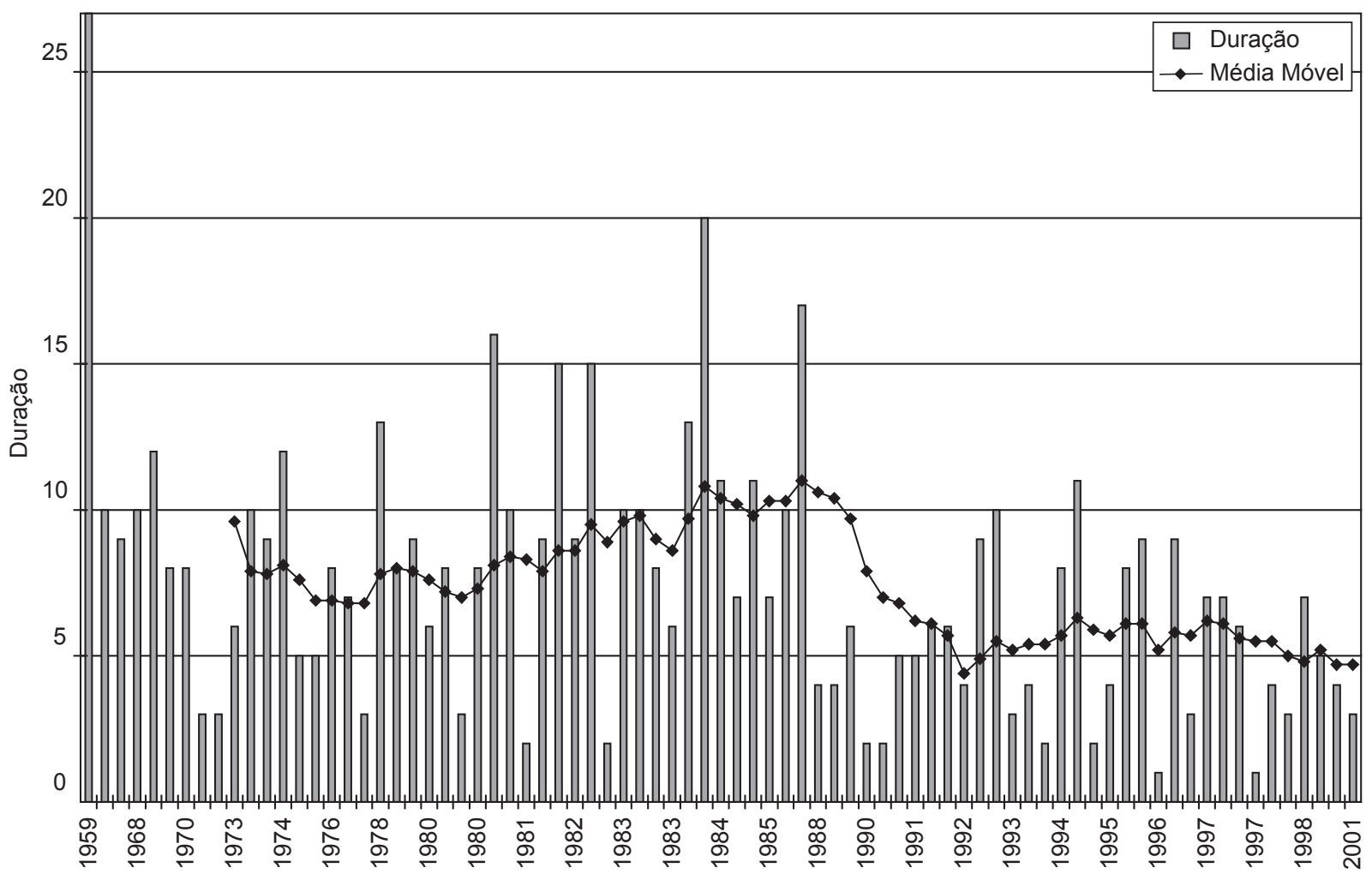

Figura 4. Ciclo de vida de modelos produzidos no mercado brasileiro. Fonte: elaborado pelos autores. 
sileiro pelas montadoras veteranas, entre 1959 e 2005 . As Figuras 3 e 4 não incorporam dados de modelos ainda em produção. A exemplo do estudo de Holweg e Greenwood (2001b), utilizou-se o conceito de remodelagem para definir o fim do ciclo de vida de um modelo.

É importante mencionar que nem sempre o início da produção do novo modelo determina o fim do ciclo de vida do antigo. Diferentes gerações de modelos de veículos "populares" convivem com freqüência no mercado brasileiro, conforme analisado mais adiante neste artigo.

Nota-se, na Figura 4, que o ciclo de vida dos veículos diminuiu, na década de 90 , influenciado pela abertura econômica presenciada no Brasil nessa época. Enquanto que nos anos 80 um veículo demorava cerca de 10 anos para ser remodelado, a partir da década seguinte esse valor foi reduzido para menos de sete anos.

\subsection{Variedade de atributos dos modelos de veículos}

Muitas empresas optam por oferecer grande variedade de produtos com o intuito de aprimorar a resposta às necessidades dos consumidores (Pine II, 1993). A idéia é equilibrar a oferta de produtos e os desejos dos clientes e, com isso, manter ou aumentar sua participação no mercado. Entretanto, o aumento da oferta de variedade de produtos tende a criar uma série de desafios para essas empresas, tais como: variações nos tempos de operação ao longo das estações de trabalho, maiores estoques, planejamento da produção mais complexo e redução do volume por componente, o que tende a aumentar os custos de produção (Fisher e Ittner, 1999). Para Pil e Holweg (2004), esses desafios também refletem no aumento da complexidade das operações envolvidas nas cadeias de suprimentos da indústria automotiva, devendo, portanto, associar o aumento dessa oferta de variedades a estratégias que visem uma minimização dessa complexidade, estratégias essas que são discutidas na Seção 4 deste artigo.

Batchelor apud Howard et al. (2001) define variedade como sendo a combinação de opções de produto oferecida ao cliente. Esta definição é semelhante à apresentada em Pil e Holweg (2004) para variedade externa, definição esta que, no contexto da indústria automotiva, consiste no número de combinações possíveis oferecidas para um modelo de veículo, baseado nos seguintes conjuntos de opções:

- Tipo de carroceria: esta opção incorpora ao conceito de estilo de carroceria, descrito na seção 3.1 , as variações do número de portas existentes no modelo;

- Powertrain: conjunto formado pelo motor (cilindrada e combustível utilizado) e pela transmissão (automática, semi-automática e manual);

- Paint-and-trim: a cor externa e o acabamento interno do veículo, itens que normalmente variam de acordo com a versão do modelo, podendo incluir o tipo de tecido para o revestimento dos bancos; e

- Opcionais de fábrica: opcionais instalados na própria fábrica, oferecidos pelas montadoras para o modelo em questão (ABS, air bag, ar-condicionado, etc.). Não estão incluídos os itens de personalização instalados nas concessionárias.

O termo variedade de atributos é utilizado neste artigo como sinônimo de variedade externa. Uma prática usual adotada pelas montadoras para atrair consumidores é fornecer uma ampla variedade de atributos para cada um de seus modelos de veículos. Os departamentos de marketing justificam tal iniciativa com base na premissa de que os atributos dos produtos determinam seu valor (Lancaster, 1990). Como uma primeira aproximação, a variedade de atributos de um modelo de veículo pode ser calculada multiplicando-se o conjunto de opções disponíveis oferecidas (Fisher e Ittner, 1999):

$N^{o}$ de combinações $=($ tipo de carroceria $) \times($ power train) $\times\left(\right.$ paint-and-trim) $\times 2^{\wedge}$ (opcionais de fabrica)

No entanto, tal fórmula raramente reflete o número real de opções que o consumidor possui, uma vez que não considera eventuais restrições (incompatibilidades e/ou vínculos) impostas pelas montadoras como, por exemplo, um modelo conversível não possuir a opção de teto solar. Assim, a simples multiplicação das variáveis resulta no total teórico de combinações possíveis, que não corresponde ao que de fato é oferecido ao cliente. Nesse contexto, Pil e Holweg (2004), bem como os autores deste artigo, realizaram uma criteriosa análise para identificar apenas as combinações que são efetivamente oferecidas aos clientes, eliminando, assim, as múltiplas opções incompatíveis entre si.

Em seu estudo sobre variedade, Pil e Holweg (2004) coletaram informações em prospectos (folders) sobre a variedade de atributos que os clientes podem efetivamente solicitar. Foram considerados os dois modelos mais vendidos das 10 principais montadoras atuantes na Europa. A Tabela 3 apresenta o resultado final do estudo.

Pode-se observar, a partir dos resultados apresentados na Tabela 3, que existe uma evidente divergência entre que variedade de atributos cada montadora acredita ser necessário oferecer, até mesmo ao se compararem modelos concorrentes em um mesmo segmento de mercado. Em alguns casos, chega-se a um total de variações muito acima do que a empresa pode vir a conseguir vender ao longo do ciclo de vida de seus produtos, o que implica em muitas combinações não serem produzidas. Em geral, na Europa as montadoras costumam oferecer um número maior de variações conforme se aumenta o valor (ou a sofisticação) do modelo.

Nota-se ainda que os fabricantes japoneses tendem a oferecer menos variações em seus modelos. Em seguida 
Tabela 3. Variações de modelos de veículo efetivamente oferecidas na Europa. Fonte: adaptado de Pil e Holweg (2004).

\begin{tabular}{|c|c|c|c|c|c|c|}
\hline Modelo & $\begin{array}{c}\text { Tipo de } \\
\text { carroceria }\end{array}$ & Powertrain & $\begin{array}{c}\text { Paint- } \\
\text { and-trim }\end{array}$ & $\begin{array}{l}\text { Opcionais } \\
\text { de fábrica }\end{array}$ & Total de variações & $\begin{array}{l}\text { Vendas na } \\
\text { Europa em } \\
2002 \text { (unid) }\end{array}$ \\
\hline Nissan Micra & 2 & 6 & 30 & 4 & 676 & 106.428 \\
\hline Peugeot 206 & 3 & 8 & 70 & 5 & 1.739 & 596.531 \\
\hline Nissan Almera & 3 & 5 & 30 & 5 & 3.036 & 87.474 \\
\hline Toyota Yaris & 2 & 6 & 30 & 8 & 34.320 & 194.256 \\
\hline Fiat Punto & 2 & 5 & 51 & 8 & 39.364 & 416.843 \\
\hline Peugeot 307 & 4 & 8 & 70 & 9 & 41.590 & 441.468 \\
\hline Renault Clio & 2 & 10 & 57 & 9 & 81.588 & 502.497 \\
\hline Toyota Corolla & 4 & 5 & 24 & 6 & 162.752 & 139.837 \\
\hline Ford Fiesta & 2 & 5 & 57 & 13 & 1.190 .784 & 294.360 \\
\hline $\begin{array}{l}\text { Renault } \\
\text { Megane }\end{array}$ & 2 & 6 & 52 & 14 & 3.451 .968 & 261.383 \\
\hline GM Astra & 4 & 11 & 83 & 14 & 27.088 .176 & 440.567 \\
\hline GM Corsa & 2 & 9 & 77 & 17 & 36.690 .436 & 420.296 \\
\hline Ford Focus & 4 & 11 & 64 & 19 & 366.901 .933 & 523.356 \\
\hline VW Golf & 3 & 16 & 221 & 26 & 1.999 .813 .504 & 595.465 \\
\hline Fiat Stilo & 3 & 7 & 93 & 25 & 10.854 .698 .500 & 173.453 \\
\hline VW Pólo & 2 & 9 & 195 & 27 & 52.612 .300 .800 & 357.539 \\
\hline Mini (BMW) & 1 & 5 & 418 & 44 & 50.977 .207 .350 .000 .000 & 105.617 \\
\hline BMW Série 3 & 3 & 18 & 280 & 45 & 64.081 .043 .660 .000 .000 & 350.723 \\
\hline $\begin{array}{l}\text { Mercedes } \\
\text { Classe C }\end{array}$ & 2 & 16 & 312 & 59 & 1.131 .454 .740 .000 .000 .000 .000 & 254.836 \\
\hline $\begin{array}{l}\text { Mercedes } \\
\text { Classe E }\end{array}$ & 2 & 15 & 285 & 70 & 3.347.807.348.000.000.000.000.000 & 157.584 \\
\hline
\end{tabular}

vêm os fabricantes americanos (Ford e GM) e, por fim, os europeus - à exceção das montadoras francesas (Peugeot e Renault), que apresentam, em média, um nível de variedade de atributos próximo ao das japonesas. De acordo com MacDuffie et al. (1996), os fabricantes japoneses tendem a diversificar sua linha de produtos focando em determinados nichos do mercado, oferecendo muitos modelos, porém com poucas combinações possíveis, enquanto que as montadoras européias costumam adotar estratégia oposta.

Realizou-se um estudo similar, voltado ao mercado brasileiro, para avaliar a variedade de atributos oferecida pelas montadoras. A metodologia utilizada para coletar dados, assim como a amostra analisada, está descrita na Seção 2 do artigo. Os resultados obtidos são apresentados na Tabela 4. Vale ressaltar que as vendas relativas ao Renault Mégane e FIAT Marea não estavam disponíveis em ANFAVEA (2005).

É importante ressaltar que as quatro montadoras veteranas no Brasil costumam manter a produção de alguns de seus modelos antigos após o lançamento de sua nova versão. É o caso dos veículos Fiat Palio, Ford Fiesta, GM Corsa e VW Gol. Nesses casos, considerou-se um único modelo com diferentes variações de tipos de carroceria. Para o Corsa, por exemplo, tem-se 3 variações: os novos modelos hatch 5 portas e sedan 4 portas e o antigo modelo sedan 4 portas.

A Tabela 5 apresenta a comparação dos modelos avaliados em ambos os mercados (europeu e brasileiro). Os resultados indicam que o número de combinações possíveis para os veículos na Europa é bem maior do que no Brasil. Para o caso do VW Polo, por exemplo, o mercado europeu chega a ter quase 8 milhões de vezes o total de opções oferecidas em relação ao mesmo modelo vendido no Brasil. As dimensões dos mercados e o nível de exigência dos clientes podem explicar essa diferença.

É possível identificar, em linhas gerais, uma semelhança entre as estratégias adotadas pelas montadoras em ambas as regiões, porém considerando a discrepância entre ordens de grandeza do número de variações no Brasil e na Europa. Essa idéia corrobora Carvalho (p. 128, 2005): "a análise das recentes estratégias de produtos e de P\&D das cinco principais montadoras instaladas no Brasil - GM, Ford, VW, Fiat e Toyota - parece indicar a existência de evidências de uma forte associação, em termos 
Tabela 4. Variações dos modelos de veículo efetivamente oferecidas no Brasil. Fonte: elaborado pelos autores.

\begin{tabular}{|c|c|c|c|c|c|c|}
\hline Modelo & $\begin{array}{c}\text { Tipo de } \\
\text { carroceria }\end{array}$ & Powertrain & Paint-and-trim & $\begin{array}{c}\text { Opcional de } \\
\text { fábrica }\end{array}$ & $\begin{array}{c}\text { Total de } \\
\text { variações }\end{array}$ & $\begin{array}{c}\text { Vendas no } \\
\text { Brasil em } \\
2004 \text { (unid) }\end{array}$ \\
\hline Renault Mégane & 1 & 2 & 3 & 0 & 6 & não disponível \\
\hline Honda Civic & 1 & 2 & 24 & 0 & 40 & 7.192 \\
\hline GM Meriva & 1 & 1 & 21 & 18 & 49 & 20.717 \\
\hline Ford Courier & 1 & 1 & 14 & 24 & 49 & 7.051 \\
\hline $\begin{array}{l}\text { Toyota Corolla } \\
\text { (incluindo Fielder) }\end{array}$ & 2 & 4 & 28 & 0 & 49 & 42.199 \\
\hline Honda Fit & 1 & 4 & 27 & 0 & 54 & 14.961 \\
\hline GM Montana & 1 & 1 & 14 & 37 & 55 & 21.544 \\
\hline Renault Scenic & 1 & 5 & 24 & 0 & 56 & 10.942 \\
\hline $\begin{array}{l}\text { Peugeot } 307 \\
\text { (Incluindo SW) }\end{array}$ & 2 & 3 & 34 & 1 & 62 & 4.355 \\
\hline GM Vectra & 1 & 2 & 26 & 23 & 69 & 3.203 \\
\hline GM Zafira & 1 & 3 & 21 & 15 & 77 & 12.122 \\
\hline Ford Ka & 1 & 2 & 28 & 4 & 90 & 22.080 \\
\hline GM Astra & 3 & 3 & 35 & 26 & 111 & 40.050 \\
\hline GM Celta & 2 & 2 & 15 & 1 & 120 & 122.700 \\
\hline Ford EcoSport & 1 & 5 & 48 & 3 & 152 & 38.741 \\
\hline Ford Focus & 2 & 3 & 24 & 10 & 156 & 17.345 \\
\hline VW Santana & 1 & 3 & 6 & 13 & 168 & 7.192 \\
\hline $\begin{array}{l}\text { Peugeot } 206 \\
\text { (incluindo SW) }\end{array}$ & 3 & 3 & 28 & 3 & 188 & 36.437 \\
\hline Citröen Picasso & 1 & 3 & 17 & 3 & 296 & 11.830 \\
\hline Gm Corsa & 3 & 4 & 42 & 34 & 363 & 125.047 \\
\hline Ford Fiesta & 3 & 3 & 29 & 24 & 469 & 74.259 \\
\hline Fiat Mille Fire & 2 & 2 & 8 & 11 & 576 & 92.815 \\
\hline MB Classe A & 1 & 4 & 12 & 6 & 704 & 14.961 \\
\hline Renault Clio & 3 & 3 & 45 & 5 & 904 & 38.208 \\
\hline Citröen C3 & 1 & 2 & 14 & 6 & 1.008 & 7.753 \\
\hline $\begin{array}{l}\text { Fiat Marea (Incluin- } \\
\text { do a Weekend) }\end{array}$ & 2 & 3 & 63 & 13 & 3.312 & não disponível \\
\hline VW Saveiro & 1 & 2 & 18 & 19 & 4.192 & 17.905 \\
\hline VW Polo & 2 & 2 & 62 & 26 & 7.440 & 24.807 \\
\hline VW Parati & 1 & 3 & 44 & 32 & 9.120 & 14.961 \\
\hline VW Gol & 3 & 5 & 25 & 33 & 10.008 & 177.119 \\
\hline Audi A3 & 1 & 8 & 42 & 13 & 42.112 & 7.192 \\
\hline VW Fox & 2 & 2 & 47 & 33 & 70.496 & 54.431 \\
\hline VW Golf & 1 & 7 & 82 & 35 & 79.776 & 14.186 \\
\hline Fiat Strada & 1 & 2 & 50 & 23 & 80.832 & 29.729 \\
\hline Fiat Doblo & 1 & 2 & 32 & 29 & 85.376 & 8.012 \\
\hline Fiat Palio Weekend & 1 & 2 & 34 & 38 & 255.392 & 23.419 \\
\hline Fiat Palio & 4 & 4 & 45 & 55 & 308.960 & 128.222 \\
\hline Fiat Siena & 2 & 4 & 30 & 43 & 474.720 & 40.760 \\
\hline Fiat Stilo & 1 & 3 & 50 & 30 & 548.356 & 10.169 \\
\hline
\end{tabular}

gerais, entre as estratégias globais de produtos e a atuação local das filiais das montadoras, tanto em relação à intensidade quanto à natureza de sua participação no desenvolvimento de produtos". Dessa forma, podemos classificar as montadoras em dois grupos: a) montadoras que oferecem um número baixo ou médio de variações - Ford, GM, Peugeot, Renault e Toyota; e b) montadoras que oferecem muitas variações - VW e Fiat. A exceção identificada é o Ford Focus, que possui muitas variações possíveis na Europa e poucas no Brasil. 
Tabela 5. Comparação das variedades efetivamente oferecidas na Europa e no Brasil. Fonte: elaborado pelos autores.

\begin{tabular}{|c|c|c|c|c|c|c|c|c|}
\hline Modelo & & $\begin{array}{c}\text { Tipo de } \\
\text { carroceria }\end{array}$ & $\begin{array}{c}\text { Power- } \\
\text { train }\end{array}$ & $\begin{array}{c}\text { Paint- } \\
\text { and-trim }\end{array}$ & $\begin{array}{l}\text { Opcionais } \\
\text { de fábrica }\end{array}$ & Total de variações & $\begin{array}{c}\text { Vendas na } \\
\text { Europa } \\
\text { em } 2002 \\
\end{array}$ & $\begin{array}{c}\text { Vendas no } \\
\text { Brasil em } 2004\end{array}$ \\
\hline \multirow[t]{2}{*}{ Fiat Stilo } & Europa & 3 & 7 & 93 & 25 & 10.854 .698 .500 & 173.453 & \\
\hline & Brasil & 1 & 2 & 62 & 30 & 548.356 & & 10.169 \\
\hline \multirow[t]{2}{*}{ Ford Fiesta } & Europa & 2 & 5 & 57 & 13 & 1.190 .784 & 294.360 & \\
\hline & Brasil & 3 & 3 & 29 & 24 & 469 & & 74.259 \\
\hline \multirow[t]{2}{*}{ Ford Focus } & Europa & 4 & 11 & 64 & 19 & 366.901 .933 & 523.356 & \\
\hline & Brasil & 2 & 3 & 24 & 10 & 156 & & 17.345 \\
\hline \multirow[t]{2}{*}{ GM Astra } & Europa & 4 & 11 & 83 & 14 & 27.088 .176 & 440.567 & \\
\hline & Brasil & 3 & 3 & 35 & 26 & 111 & & 40.050 \\
\hline \multirow[t]{2}{*}{ GM Corsa } & Europa & 2 & 9 & 77 & 17 & 36.690 .436 & 420.296 & \\
\hline & Brasil & 3 & 4 & 42 & 34 & 363 & & 125.047 \\
\hline \multirow{2}{*}{$\begin{array}{l}\text { Peugeot } \\
206\end{array}$} & Europa & 3 & 8 & 70 & 5 & 1.739 & 596.531 & \\
\hline & Brasil & 3 & 3 & 28 & 3 & 188 & & 36.437 \\
\hline \multirow{2}{*}{$\begin{array}{l}\text { Peugeot } \\
307\end{array}$} & Europa & 4 & 8 & 70 & 9 & 41.590 & 441.468 & \\
\hline & Brasil & 2 & 3 & 34 & 1 & 62 & & 4.355 \\
\hline \multirow{2}{*}{$\begin{array}{l}\text { Renault } \\
\text { Clio } \\
\end{array}$} & Europa & 2 & 10 & 57 & 9 & 81.588 & 502.497 & \\
\hline & Brasil & 3 & 3 & 45 & 5 & 904 & & 38.208 \\
\hline \multirow{2}{*}{$\begin{array}{l}\text { Renault } \\
\text { Mégane }\end{array}$} & Europa & 2 & 6 & 52 & 14 & 3.451 .968 & 261.383 & \\
\hline & Brasil & 1 & 2 & 3 & 0 & 6 & & não disponível \\
\hline \multirow{2}{*}{$\begin{array}{l}\text { Toyota } \\
\text { Corolla }\end{array}$} & Europa & 4 & 5 & 24 & 6 & 162.752 & 139.837 & \\
\hline & Brasil & 2 & 4 & 28 & 0 & 49 & & 42.199 \\
\hline \multirow[t]{2}{*}{ VW Golf } & Europa & 3 & 16 & 221 & 26 & 1.999 .813 .504 & 595.465 & \\
\hline & Brasil & 1 & 7 & 82 & 35 & 79.776 & & 14.186 \\
\hline \multirow[t]{2}{*}{ VW Polo } & Europa & 2 & 9 & 195 & 27 & 52.612 .300 .800 & 357.539 & \\
\hline & Brasil & 2 & 2 & 62 & 26 & 7.440 & & 24.807 \\
\hline
\end{tabular}

\section{Estratégias adotadas pelas montadoras}

Conforme apresentado anteriormente em 3.1 e 3.2, as montadoras de veículos, de uma forma geral, têm desenvolvido e produzido um número maior de modelos associados a um maior número de estilos de carrocerias e a um menor ciclo de vida. Para fazer face a estas questões, desde a década de 70, várias ferramentas e conceitos foram desenvolvidos na indústria autom otiva para aprimorar o compartilhamento de peças e para diminuir o tempo de desenvolvimento dos produtos. Entre estas ferramentas e conceitos, a estratégia de plataformas de veículos é provavelmente a melhor resposta para combinar, buscando um bom trade off, o aumento de opções para o consumidor final ao conseqüente crescimento da complexidade na produção e na distribuição do veículo, conforme preconizado pelo Projeto de Pesquisa Europeu 3-Day Car (Howard, 2000).

Um terceiro aspecto analisado na seção anterior é a oferta de variedade de atributos para modelos de veículo. Esta variedade traz sérios problemas para as montadoras quando estas produzem com base em previsões de demanda e vendem seus produtos a partir do estoque exis- tente - situação essa que ainda prevalece, de forma geral, no cenário automotivo mundial, especialmente no Brasil. Nesse contexto, uma alta variedade dificulta a tarefa de se encontrar, dentre os produtos em estoque, a combinação de variedades de atributos solicitada pelo cliente. Dessa forma, os fabricantes de automóveis enfrentam o dilema entre reduzir as opções, de modo a minimizar os níveis de estoque, ou, então, deixar de atender às especificações desejadas pelo cliente (Pil e Holweg, 2004). Para Pil e Holweg, uma forma de contornar este dilema é o desenvolvimento de estratégias como configuração tardia (late configuration) e pacotes de opcionais (option bundling).

Sendo assim, a presente seção analisa, a seguir, as três estratégias mencionadas: a estratégia das plataformas, a configuração tardia e pacotes de opcionais.

\subsection{Estratégia de plataformas}

Howard (2000) define plataforma como o projeto de produto a partir do qual diferentes produtos derivados podem ser desenvolvidos em um período de tempo significativo. A adoção de plataformas mundiais vem sendo largamente utilizada pelas montadoras de forma a obter os benefícios de compras em escala de partes comuns e de 
economia nos tempos e custos atrelados a projetos de veículos, compartilhando, assim, um projeto com diversos modelos e marcas (Muffato, 1999). As montadoras passam com isso a produzir diversos modelos com a mesma plataforma, ampliando seus ganhos de escala sem perder a necessária customização de cada modelo (Bremner, 2000; Freyssenet e Lung, 2000), permitindo desacoplar a variedade industrial (componentes e autopeças) da variedade de atributos (modelos de veículos fornecidos ao cliente final). Este desacoplamento facilita a gestão da complexidade ao longo da cadeia de suprimentos.

O caso da Volkswagen exemplifica a estratégia de plataformas mundiais. Esta montadora estabeleceu, em seu programa de reestruturação de 1994, a meta de substituição das 16 plataformas existentes por apenas 4 novas plataformas, que serviriam para todos os modelos produzidos pelo grupo VW - Audi, Seat e Skoda, além da própria VW (Carvalho, 2005). A Plataforma A4 da VW serve de base para modelos como: VW Golf, VW Bora, VW Beatle, Audi TT, Audi A3, Seat Leon, Seat Toledo e Skoda Oktavia. As demais grandes montadoras também seguem esta estratégia, valendo citar o plano da GM de reduzir de 13 para apenas 7 o número de plataformas globais para os seus automóveis e o da Renault/Nissan de reduzir de 39 para 10 plataformas globais (Winter e Zoia, 2001). A Tabela 6 apresenta a evolução entre 1990 e 2002 do número de estilos de carrocerias e plataformas no mercado europeu.

Ao contrastarmos os dados da Tabela 1 com os da Tabela 6, verificamos que o número de estilos de carrocerias cresceu $103 \%$ entre 1990 e 2002, enquanto que o número de plataformas diminui $23 \%$ no mesmo período, acarretando num aumento de $165 \%$ na relação do número de estilos de carrocerias produzidos por plataforma. Os ganhos de escala oriundos da plataforma também são ilustrados pelo aumento da produção média na Europa de estilos de carrocerias por plataforma, que cresceu $42 \%$.

A adoção da estratégia de plataformas também é presente no Brasil. Todavia, a chegada dos novos entrantes, a partir da década de 90, leva a uma análise diferenciada. A Tabela 7 ilustra o caso brasileiro, destacando o comportamento diferenciado das montadoras veteranas.

O comportamento da indústria brasileira não segue o da indústria européia no que tange às plataformas. No Brasil, apesar das montadoras que produzem localmente seguirem esta estratégia global, o número de plataformas apresentou um aumento, conforme apresentado na Tabela 7. Isto se deve em parte ao fato de plataformas antigas conviverem com novas plataformas no Brasil. Deve-se também notar que, no início dos anos 80 , as montadoras veteranas não ocupavam muitos segmentos de mercado e, por isso, necessitavam de poucas plataformas. Hoje, estas montadoras atuam em vários segmentos intermediários, oferecendo novos modelos e precisando assim introduzir a produção de novas plataformas na região. Essa busca de novos segmentos de mercado no Brasil deve-se muito ao fato do mercado brasileiro estar em crescimento. Vale mencionar também a participação das novas entrantes que começaram a produzir na segunda metade dos anos 90 , introduzindo, assim, novas plataformas no mercado. Os números das plataformas introduzidas oriundas das novas entrantes figuram nos dados de 2000 e 2004 da Tabela 7

Tabela 6. Estilo de carrocerias e plataformas com enfoque no mercado europeu. Fonte: adaptado de Pil e Holweg (2004).

\begin{tabular}{|c|c|c|c|c|c|c|c|c|c|c|}
\hline & 1990 & 1995 & 1996 & 1997 & 1998 & 1999 & 2000 & 2001 & 2002 & $\begin{array}{c}\text { Variação } \\
1990-2002 \\
\end{array}$ \\
\hline $\mathrm{N}^{\circ}$ Plataformas & 60 & 60 & 57 & 56 & 53 & 49 & 43 & 43 & 46 & $-23 \%$ \\
\hline $\begin{array}{l}\text { Média de Estilos de } \\
\text { carroc./Plataforma }\end{array}$ & 1,5 & 2,3 & 2,4 & 2,6 & 3,0 & 3,2 & 3,9 & 4,1 & 3,9 & $165 \%$ \\
\hline $\begin{array}{l}\text { Produção média por } \\
\text { plataforma (mil veículos) }\end{array}$ & 190 & 166 & 178 & 191 & 218 & 244 & 285 & 283 & 269 & $42 \%$ \\
\hline
\end{tabular}

Tabela 7. Estilo de carrocerias e plataformas com enfoque no mercado brasileiro. Fonte: elaborado pelos autores.

\begin{tabular}{lrrrrrrc}
\hline & $\mathbf{1 9 8 0}$ & $\mathbf{1 9 8 5}$ & $\mathbf{1 9 9 0}$ & $\mathbf{1 9 9 5}$ & $\mathbf{2 0 0 0}$ & $\mathbf{2 0 0 4}$ & $\begin{array}{c}\text { Variação } \\
\mathbf{1 9 8 0 - 2 0 0 4}\end{array}$ \\
\hline $\mathrm{N}^{\circ}$ Plataformas (veteranas) & 7 & 12 & 9 & 13 & 12 & 15 & $114,3 \%$ \\
Produção média por plataforma (mil veículos, veteranas) & 134 & 69 & 87 & 110 & 115 & 115 & $-14,2 \%$ \\
$\mathrm{~N}^{\circ}$ Plataformas (todas montadoras) & 7 & 12 & 9 & 13 & 17 & 24 & $242,9 \%$ \\
$\begin{array}{l}\text { Produção média por plataforma (mil veículos, todas } \\
\text { montadoras) }\end{array}$ & 134 & 69 & 87 & 110 & 88 & 82 & $-38,8 \%$ \\
Produção no Brasil (mil veículos, todas montadoras) & 939 & 827 & 785 & 1.429 & 1.501 & 1.979 & $110,8 \%$ \\
\hline
\end{tabular}


e justificam a redução da produção média de veículos por plataforma no Brasil entre 1995 e 2004, apesar do significativo aumento da produção de automóveis de passeio e comerciais leves no país. Enquanto que as veteranas introduziram apenas 2 plataformas novas entre $1995 \mathrm{e}$ 2004, as novas entrantes introduziram 9 plataformas.

A adoção de estratégias de plataformas mundiais vem implicando em uma crescente participação de fornecedores nas etapas iniciais dos projetos de novos veículos, por meio do desenvolvimento de capabilidades com o Early Supply Involvement - ESI (Freyssenet e Lung, 2000) e o Co-design. O ESI requer a escolha do fornecedor antes ou durante a concepção do projeto de um determinado produto, envolvendo-o em várias fases de seu desenvolvimento (Dowlatshahi, 1998). A implementação do ESI gera uma melhora na qualidade do produto, uma redução nos tempos de desenvolvimento de produtos e em seus respectivos custos (Bidault e Butler, 1995). No Co-design o fornecedor não só está envolvido nas etapas iniciais dos projetos, como também no desenvolvimento e concepção do projeto em si (De Toni e Nassimbeni, 2001).

Existe uma forte relação entre a estratégia de plataformas e a de modularização. PricewaterhouseCoopers (2002), por exemplo, em seu estudo sobre tendências na indústria automotiva, aponta a modularização como um grande facilitador para a implementação e adoção de plataformas mundiais. A modularização está baseada na idéia da montagem dos veículos pelas montadoras a partir de subconjuntos montados (os módulos) e não peças separadas. A idéia central dessa estratégia é a simplificação da montagem final, visando, principalmente, à redução de custos, ao aumento da eficiência de operações de montagem e dos investimentos das montadoras para a construção de novas plantas (Alvarez et al., 2002). De acordo com Schonberger apud Corrêa (2001), uma planta de automóveis deveria lidar com apenas cerca de 100 componentes para ser eficiente. Uma planta tradicional lida com uma ordem de 10 mil componentes por veículo, o que faz com que as montadoras tenham um gasto desnecessário com atividades que não agregam valor, como estoque e movimentação de matérias-primas e/ou produtos em processo, logística e planejamento de compras e de produção. A redução do número de componentes lidados por uma montadora é um dos principais benefícios proporcionados pela modularização.

Winter e Zoia (2001) sublinham o fato de que a estratégia de modularização pode possibilitar uma maior diferenciação dos modelos de veículos que a própria estratégia de plataforma. Mesmo assim, ambas as estratégias podem ser implementadas em conjunto. A Volkswagen, por exemplo, vem alinhando a sua estratégia de redução de plataformas com uma estratégia de modularização baseada no desenvolvimento de 11 módulos chave para os seus veículos. Estes módulos podem inclusive atender a veículos de diferentes segmentos da montadora, como é o caso de alguns módulos que atendem ao VW Golf e ao VW Passat, modelos de plataformas diferentes.

\subsection{Configuração tardia (late configuration)}

O elevado nível de estoque, especialmente de produtos acabados, é um dos grandes problemas enfrentados pela indústria automotiva mundial. Em função da forma tradicional de produção com base em previsões de demanda, algumas montadoras estão adotando a estratégia de retardar atividades ao longo da cadeia de suprimentos, para realizar a configuração do produto mais próxima ao ponto de pedido do cliente (van Hoek, 2001). Assim, ao realizar a configuração tardia, as montadoras conseguem reduzir a complexidade interna de seus processos de montagem. No momento em que os centros de distribuição ou concessionárias tornam-se responsáveis por tal configuração, reduz-se o número de opções do produto final que o sistema da montadora deve possuir (Pil e Holweg, 2004).

Observa-se que esta estratégia é largamente utilizada pelas montadoras no Brasil. Opções como revestimento dos bancos em couro e sistemas de som são alguns exemplos de itens cujas instalações estão sendo retardadas pelas montadoras, optando por fazê-las em suas concessionárias autorizadas. Apenas em algumas versões (normalmente as versões de luxo) estas configurações costumam ocorrer nas fábricas.

Os modelos Celta e Corsa são um bom exemplo dessa prática. Por pertencer ao segmento de modelos populares, a GM optou por apenas um único opcional do Celta a ser instalado na fábrica: o ar-condicionado. Dessa forma, ela conseguiu simplificar seus processos e reduzir complexidade em sua linha de montagem. Itens como vidros, travas e retrovisores com ajuste elétrico, rodas de liga leve e direção hidráulica são instalados nas concessionárias da GM, o que, no caso do Corsa, podem ser instalados na fábrica de São José dos Campos. Conforme é mostrado na Tabela 4, enquanto o Celta possui apenas um opcional, o Corsa tem 34. Cabe ressaltar que os cinco centros de distribuição da GM dedicados ao Celta não realizam a configuração tardia. Esse fato pode ser generalizado para quase todas as montadoras no Brasil. Já na Europa, os centros de distribuição auxiliam no desenvolvimento da estratégia de configuração tardia, pois, freqüentemente, são eles os responsáveis pela instalação dos itens de personalização.

A Tabela 8 apresenta o número de variações oferecidas para o modelo GM Celta. Diferentemente da Tabela 4, o modelo da GM, nesta tabela, está discriminado pelas versões e incorpora em uma de suas colunas os números referentes aos itens de personalização, opcionais que são instalados nas concessionárias e não nas fábricas. $\mathrm{O}$ número de itens de personalização oferecidos no Celta varia entre 31 e 36 unidades, dependendo da versão. Consequientemente, o total de combinações oferecidas aos 
clientes passou, com o auxílio da configuração tardia, de 120 para cerca de $5 \times 10^{11}$. Uma análise similar foi feita para o GM Astra, que por sua vez, com a inclusão dos itens de personalização, teve o número total de variações expandida de 111 para $7 \times 10^{4}$.

\subsection{Pacotes de opcionais (option bundling)}

Outra forma encontrada pelas montadoras para reduzir os efeitos da variedade de atributos de seus modelos é agrupar os opcionais em pacotes - em vez de vendê-los separadamente - de modo a reduzir a complexidade. $\mathrm{Ou}$ seja, os pacotes reduzem a escolha a um predeterminado conjunto de opções. Segundo Batchelor apud Pil e Holweg (2004), a principal razão para o uso de pacotes de opcionais é a redução dos erros de previsão de vendas.

No Brasil, observam-se claramente duas vertentes em relação à estratégia de pacotes de opcionais: montadoras que a utilizam e outras que não. Além disso, é necessário distinguir o uso desta estratégia entre as montadoras veteranas e as novas entrantes.

Das quatro montadoras veteranas, duas (GM e Ford) oferecem apenas um predeterminado número de pacotes de opcionais para seus clientes. Assim, se o cliente desejar que seu veículo possua air bag, deverá comprar um pacote que inclua ainda, por exemplo, direção hidráulica, vidros elétricos, rodas de liga leve e $\mathrm{CD}$ player. Como resultado, a elevada oferta de variações de atributos disponíveis é transformada em um reduzido número de combinações oferecidas ao cliente.

Uma característica interessante observada é que os modelos mais baratos e que possuem uma maior fatia de mercado, como Corsa e Fiesta, são oferecidos com maior número de variações (363 e 469, respectivamente) que outros mais caros, como Astra, Vectra e Focus (111, 69 e 156, respectivamente). A principal razão dessa situação é que os modelos mais caros são ofertados com maior número de itens como sendo de série, isto é, as versões já vêm mais "completas". Por outro lado, o mercado dos modelos mais baratos é bem maior, possuindo uma quantidade representativa de vendas tanto de modelos Corsa e
Fiesta "completos" (com ar-condicionado, air bag e outros itens) quanto dos mesmos modelos em suas versões mais básicas, com poucos opcionais.

Vale mencionar que a GM Brasil adotou a estratégia de pacotes recentemente em seu modelo Astra. No final dos anos 90, esse modelo era oferecido ao mercado com um número de variações muito maior que o reduzido número atual. No Reino Unido, aconteceu um caso semelhante. A segunda geração do Astra, que iniciou o seu ciclo de vida em 1984, era oferecida com um total de 53 milhões de variações. Este número caiu para apenas 77 mil, com o início da terceira geração em 1993, e voltou a subir para 55 milhões, no início da quarta geração do Astra em 1998 (Holweg e Greenwood, 2001a).

Uma questão que surge ao se utilizar pacotes diz respeito a como o mercado reage a tal estratégia. Para responder a esta questão, será analisado o caso da Ford. A Tabela 9 apresenta a relação entre o número de combinações existentes nos seus modelos mais vendidos no mercado brasileiro (coluna 2) e o total de variações responsáveis por $50 \%$ dessas vendas (coluna 3 ). Os valores apresentados nesta última coluna foram obtidos no maior distribuidor Ford da Região do Rio e Janeiro/Espírito Santo (pertencente a um grande distribuidor multimarcas), responsável por 6 concessionárias autorizadas desta

Tabela 9. Variações de atributos de modelos da Ford e sua relação com vendas. Fonte: elaborado pelos autores.

\begin{tabular}{lcc}
\hline Modelo & $\begin{array}{c}\text { Número total } \\
\text { de variações, } \\
\text { excluindo a cor } \\
\text { do veículo }\end{array}$ & $\begin{array}{c}\text { Número total de } \\
\text { variações, ex- } \\
\text { cluindo as cores, } \\
\text { responsável por } \\
\text { 50\% das vendas }\end{array}$ \\
\hline Ford Ka & 24 & 8 \\
Ford Fiesta Hatch & 20 & 8 \\
Ford Fiesta Sedan & 39 & 8 \\
Ford Focus Hatch & 13 & 2 \\
Ford Focus Sedan & 13 & 1 \\
Ford EcoSport & 19 & 2 \\
\hline
\end{tabular}

Tabela 8. Variações das versões do veículo GM Celta. Fonte: elaborado pelos autores.

\begin{tabular}{lllcccccc}
\hline & Versão Powertrain & $\begin{array}{c}\text { Paint- } \\
\text { and-Trim }\end{array}$ & Opcionais & $\begin{array}{c}\text { Número de } \\
\text { itens de per- } \\
\text { sonalização }\end{array}$ & $\begin{array}{c}\text { Combinaçães } \\
\text { dos itens de } \\
\text { personalização }\end{array}$ & $\begin{array}{c}\text { Total sem } \\
\text { personalização }\end{array}$ & $\begin{array}{c}\text { Total com } \\
\text { personalização }\end{array}$ \\
\hline Celta & Life & 2 & 5 & 2 & 34 & 6.794 .772 .480 & 60 & $2,17 \mathrm{E}+11$ \\
2 Portas & Spirit & 2 & 5 & 2 & 33 & 3.397 .386 .240 & & \\
& Super & 2 & 5 & 2 & 31 & 679.477 .248 & & $3,26 \mathrm{E}+11$ \\
\hline Celta & Life & 2 & 5 & 2 & 36 & 10.192 .158 .720 & 60 & \\
4 Portas & Spirit & 2 & 5 & 2 & 35 & 5.096 .079 .360 & & \\
& Super & 2 & 5 & 2 & 33 & 1.019 .215 .872 & & $5,44 \mathrm{E}+11$ \\
\hline
\end{tabular}


montadora. O número de cores oferecidas foi excluído do total de variações de atributos, pois tal informação não consta na base de dados do distribuidor analisado.

Nota-se que $50 \%$ dos consumidores optaram por apenas duas variações do EcoSport e no máximo duas para o Focus. Estes são indícios de que não deve ter havido perda de vendas nestes modelos, pois os compradores optaram justamente por poucos modelos, assim, uma oferta maior não deveria alterar esta opção de compra. Por outro lado, os modelos Ka e Fiesta (de menor valor agregado) são oferecidos com uma maior variedade, mas suas vendas tendem a ser melhor distribuídas. Assim, há indícios de que a estratégia de oferta de pacotes de opcionais da Ford atende às necessidades de seus clientes, pois a venda dos modelos com menor oferta de opcionais tende a concentrar-se em poucos modelos, enquanto que o oposto acontece nos modelos com maior oferta de opcionais.

A Volkswagen e a Fiat não trabalham com pacotes de opcionais. Conseqüentemente, aumenta-se o número total de variações oferecidas aos clientes destas montadoras. Mesmo assim, ainda há algumas restrições de incompatibilidade e vínculo entre dois ou mais opcionais. Como pode ser visto na Tabela 4, o total de variações encontradas nos modelos da Ford e GM não chega a 500. Por outro lado, a VW chega a oferecer quase 80 mil variações para o Golf e a Fiat mais 500 mil para o Stilo. Apesar de esses últimos números serem grandes para o mercado brasileiro, são pequenos quando comparados com os números dos respectivos modelos oferecidos ao mercado europeu.

As novas entrantes iniciaram suas atividades produtivas no Brasil no final dos anos 90, oferecendo poucos modelos e opcionais ao mercado, conforme mostrado na Tabela 4. Dessa forma, o uso de pacotes não se faz necessário. Todavia, as novas entrantes francesas e japonesas seguem, no mercado brasileiro, a estratégia adotada para o mercado europeu no que tange ao número de variações oferecidas, número este sempre reduzido quando comparado ao oferecido pelas outras montadoras.

\section{Conclusão}

O presente artigo teve por primeiro objetivo analisar as tendências relacionadas ao cenário mercadológico enfrentado pelas montadoras de veículos. Os mercados brasileiro e europeu apresentaram um crescimento da média de modelos produzidos pelas principais montadoras, atingindo hoje um número próximo de oito modelos por montadora. Ao analisarmos o tempo de ciclo de vida dos modelos de veículos, foi possível verificar uma significativa redução em ambos os mercados. Esta redução iniciou-se na Europa ao final dos anos 70, enquanto que no Brasil ela aconteceu apenas nos anos 90. A análise da variedade de atributos existentes para os modelos de veículos também fez parte do primeiro objetivo deste artigo. Nesta análise, pôde-se notar que as montadoras oferecem ao mercado europeu um total de variedades muito maior que o oferecido ao mercado brasileiro. Apesar das diferenças numéricas, verificou-se que as montadoras agem de forma coerente em ambos os mercados. Ao agrupar as montadoras de acordo com o número total de variedades de atributos oferecidos a cada mercado e levar em consideração a realidade de cada mercado, pôde-se verificar que as montadoras que oferecem poucas variedades na Europa também o fazem no Brasil, guardadas as proporções numéricas. É o caso das montadoras japonesas e francesas. $\mathrm{O}$ mesmo acontece com as montadoras que oferecem muitas variedades, como a Fiat e a VW, que o fazem em ambos os mercados. No caso do mercado europeu, existiu um grupo de montadoras formado pela BMW e Mercedes, cujo número total de variações superou a ordem de $10^{16}$, chegando à ordem de $10^{24}$ para o Modelo Classe E da Mercedes. Deve-se levar em conta, porém, que esses modelos de veículos pertencem a segmentos exclusivos de mercado e que seus consumidores exigem que uma ampla variedade de atributos seja oferecida de modo que suas diferentes necessidades e desejos sejam atendidos em um veículo personalizado. Entretanto, os custos de estocar as diversas peças e componentes, de modo a atender tais necessidades dos consumidores, dificultam a produção com base em previsões de demanda. A principal forma encontrada pelas montadoras para minimizar este problema é oferecer aos seus clientes a compra do veículo desejado produzido sob encomenda. A maior parte dos veículos da Mercedes e da BMW vendidos na Europa, principalmente na Alemanha, é produzida sob encomenda.

Muitas empresas aumentam a variedade de seus produtos na tentativa de melhor atender às necessidades de seus clientes (Pine II, 1993). De fato, Lancaster (1990) considera que a escolha de um maior número de variedades pode influenciar no aumento das vendas. Entretanto, Pil e Holweg (2004) encontraram uma correlação negativa de 0,23 entre as vendas e o total de atributos existentes para os modelos de veículos analisados para o mercado europeu (ver Tabela 3). Fazendo esse mesmo cálculo, considerando o mercado brasileiro, tendo como base os números da Tabela 4, obtem-se como resultado uma correlação de 0,43 , conforme apresentado na Tabela 10 . Ou seja, em ambos os casos não se encontra uma correlação clara entre vendas e número de variedades.

A Tabela 10 apresenta ainda a correlação para as quatro montadoras veteranas. Os resultados mostram que a GM

Tabela 10. Correlação entre o volume de vendas e o total de variações de atributos oferecidos. Fonte: elaborado pelos autores.

\begin{tabular}{ccccc}
\hline Mercado & GM & Ford & VW & Fiat \\
\hline 0,43 & 0,73 & 0,94 & $-0,13$ & 0,52 \\
\hline
\end{tabular}


e, principalmente, a Ford possuem uma maior correlação (0,73 e 0,94, respectivamente) que a VW e a Fiat. Uma possível razão para tal fato é o uso, por parte das duas primeiras montadoras, de uma adequada estratégia de pacotes de opcionais. Assim, veículos dessas montadoras com maior volume de vendas tendem a serem oferecidos com um número maior de pacotes e, conseqüentemente, de variações de atributos para atender às necessidades dos clientes.

É importante mencionar que o aumento da oferta de variações repercute no aumento da complexidade das operações nas cadeias de suprimentos da indústria automotiva. Portanto, a gestão desta complexidade se faz necessária de forma a se chegar ao número ideal de variações a serem oferecidas para o mercado, sem que isso prejudique o desempenho da cadeia. Uma área a ser mais bem entendida é a questão relacionada ao custo desta complexidade. De acordo com as entrevistas realizadas no Brasil, corroboradas com os resultados obtidos na Europa, as montadoras de veículos ainda não têm um modelo preciso para mensurar o custo da complexidade oriunda, por exemplo, do acréscimo da oferta de mais uma cor para um modelo de veículo. O desenvolvimento desse modelo faz parte do âmbito do projeto ILIPT.

O segundo objetivo do artigo foi o de analisar as principais estratégias resultantes destas tendências que vêm sendo desenvolvidas e implementadas pelas montadoras nos dois mercados considerados. A estratégia de adoção e redução no número de plataformas mundiais vem sendo aplicada de forma bem clara na Europa. Já no Brasil, apesar de as montadoras que produzem localmente seguirem esta estratégia global, o número de plataformas apresentou um aumento, o que foi justificado pelo fato de coexistirem plataformas antigas e novas para alguns modelos, pelo crescimento de vendas de veículos associados a novos segmentos de mercado e pela vinda de novas montadoras para a região.

A estratégia de modularização também guiou o desenvolvimento dos projetos de vários modelos, assim como o processo de montagem desses modelos. Como exemplos, podem-se citar os casos do Smart (Hambach, França) e do GM Celta (Gravataí, Brasil).

Verificamos que não existe uma regra clara para o uso da estratégia de pacotes de opcionais para os mercados europeu e brasileiro. Para o caso brasileiro foi verificado que duas montadoras veteranas adotam esta estratégia (GM e Ford). Também foi observado que esta estratégia hoje tem sido usada de forma alternada pelas montadoras, como no caso do GM Astra.

Os resultados da pesquisa também sublinham o uso da estratégia de configuração tardia por montadoras de ambas as regiões. Vale ressaltar, porém, que, na Europa, o uso de centros de distribuição para fazer a configuração tardia é freqüente, o que, no Brasil, somente ocorre nos concessionários autorizados.

De acordo com Pil e Holweg (2004), o uso de módulos e plataformas gera melhores resultados para as montadoras que trabalham com produção sob encomenda. O objetivo fundamental do projeto ILIPT é entregar ao cliente final um veículo personalizado em, no máximo, cinco dias úteis após a sua encomenda. Para atingir tal objetivo, os pesquisadores do ILIPT preconizam o uso de plataformas e módulos. Nesta proposta, os módulos não seriam somente compartilhados por modelos pertencentes à mesma montadora, a exemplo dos modelos VW Passat e VW Golf, mas também poderiam ser utilizados por montadoras diferentes.

Por outro lado, Pil e Holweg (2004) argumentam que as estratégias de configuração tardia e pacotes de opcionais trazem maiores benefícios para empresas com produção baseada em previsões de vendas. Para estas empresas, as estratégias representam a possibilidade de reduzir as incertezas associadas às preferências dos clientes.

O projeto ILIPT tem estudado a possibilidade de descentralizar a produção de veículos, hoje feita em grandes plantas onde a escala de produção é fundamental para a geração do lucro. Desta forma, o ILIPT busca uma nova configuração na cadeia em que, possivelmente, a montagem final dos veículos, responsável por muito da personalização do veículo, seja postergada para ser feita em minifábricas próximas ao mercado consumidor, deixando para as grandes fábricas a produção das partes comuns (módulos).

O ILIPT se insere em uma discussão em voga na indústria automotiva, o uso das estratégias de operações de produção sob encomenda e produção baseada em previsões de vendas, que está sendo largamente abordado. Está claro que, para modelos de alto valor agregado e de elevado índice de personalização no mercado europeu, a produção local sob encomenda é a estratégia mais apropriada (vide os casos da Mercedes e da BMW na Alemanha). Todavia, ainda não existem elementos suficientes para analisar o uso dessa estratégia em modelos de veículos de baixo valor agregado e reduzido índice de personalização produzidos em países emergentes como o Brasil. Para responder a esta questão, o ILIPT tem analisado o comportamento dos dois mercados. O presente artigo é parte desta análise e apresenta indícios de que existem muitas diferenças entre estes dois mercados que devem ser consideradas em um estudo posterior.

\section{Agradecimentos}

Os autores agradecem o apoio da CAPES (bolsa PRODOC), da FAPERJ (projeto E-26/151.186/2003), do CNPq (projetos 481945/2004-0 e 308790/2003-0 e bolsa de Mestrado) e às contribuições dos referees desta revista. 


\section{Referências Bibliográficas}

ALVAREZ, R. R.; PROENÇA, A.; ANDRÉREZ, D. P. S. Rio automotivo: elementos da realidade e perspectivas de desenvolvimento. SEBRAE/RJ, Rio de Janeiro, 2002.

ASSOCIAÇÃO NACIONAL DOS FABRICANTES DE VEÍCULOS AUTOMOTORES (ANFAVEA). Anuário Estatístico. Disponível em: <http://www.anfavea.com. br>. Acesso em: 20 de março 2005.

BIDAULT F.; BUTLER C. Buyer - Supplier Cooperation for Effective Innovation. M2000 Executive Report, Lausanne, n. 17, set. 1995.

BREMNER, R. Big, bigger, biggest. Automotive World, n. 6, p. 36-43, 2000.

CARVALHO, E. G. Globalização e estratégias competitivas na indústria automobilística: uma abordagem a partir das principais montadoras instaladas no Brasil. Gestão \& Produção, São Carlos, v. 12, n. 1, p. 121-133, jan./ abr. 2005.

CONSONI, F. Relatório Setorial, Setor Automóveis. FINEP, Rede DPP. 2004.

CORRÊA, H. L. The VW Resende (Brazil) plant modular consortium SCM model after 5 years of operation. In: Annual Conference of the Production and Operations Management Society, 12., 2001, Orlando, Proceedings... Orlando: mar./abr. 2001.

DE TONI, A.; NASSIMBENI, G. A method for the evaluation of suppliers' co-design effort. International Journal of Production Economics, v. 72, n. 2, p. 169-180, jul. 2001.

DOWLATSHAHI, S. Implementing early supplier involvement: a conceptual framework. International Journal of Operations \& Production Management, v. 18, n. 2, p. 143-167, 1998.

FISHER, M.; ITTNER, C. The impact of product variety on automobile assembly operations: empirical evidence and simulation analysis. Management Science, v. 45, n. 6, p. 771-786, jun. 1999.

FREYSSENET M.; LUNG Y. Between Globalization and Regionalization: What is the Future of Motor Industry? In: Humphrey J., Lecler Y., Salerno M. (eds.) Global Strategies and Local Realities: The Auto Industry in Emerging Markets. Basingstoke: Macmillan, 2000.
HOLWEG, M.; GREENWOOD, A. Product variety, life cycles and rate of innovation: trends in the UK automotive industry. World Automotive Manufacturing, n. 36, p. 12-16, abril 2001a.

HOLWEG, M.; GREENWOOD, A. Product Variety, Life Cycles, and Rate of Innovation - Trends in the UK Automotive Industry. Research Paper. Cardiff: University of Cardiff, 2001b.

HOWARD, M. Production and Process Technology: The Impact of Vehicle Design on Rapid Build to Order. Research Paper. Bath: University of Bath, 2000.

HOWARD, M.; YOUNG, K.; GRAVES, A. Towards the 3Daycar: vehicle design and its impact on rapid build-toorder. International Journal of Vehicle Design, v. 26, n. 5, p. 455-468, 2001.

J D POWERS - LMC, European Model Life Cycle Dynamics, Oxford, 2000.

LANCASTER, $\mathrm{K}$. The economics of product variety: a survey. Marketing Science, v. 9, n. 3, p. 189-206, 1990.

MACDUFFIE, J.; SETHURAMAN, K.; FISHER, M. Product variety and manufacturing performance: evidence from the International Automotive Assembly Plant Study. Management Science, v. 42, n. 3, p. 350-369, mar. 1996.

MUFFATTO, M. Platform strategies in international new product development, International Journal of Operations \& Production Management, v. 19, n. 5-6, p. 449-459, 1999.

PIL, F.; HOLWEG, M. Linking product variety to orderfulfillment strategies. Interfaces, v. 34, n. 5, p. 394-403, set./out. 2004.

PINE II, J. B. Mass Customization: The New Frontier in Business Competition. Cambridge, MA: Harvard Business School Press, 1993.

PRICEWATERHOUSECOOPERS. 2000 Global Automotive Financial Review: an Overview of Industry Trends and Financial Reporting Practices, Pricewaterhouse Coopers, 2002.

VAN HOEK, R. The rediscovery of postponement a literature review and directions for research. Journal of Operations Management, v. 19, n. 2, p. 161-184, fev. 2001.

WINTER, D.; ZOIA, D. Rethinking platform engineering. Ward's Auto World, v. 37, n. 3, p. 46-50, mar. 2001. 


\title{
TRENDS AND STRATEGIES IN THE AUTOMOTIVE INDUSTRY: A COMPARATIVE STUDY OF BRAZILIAN AND EUROPEAN MARKETS
}

\begin{abstract}
The automotive industry is undergoing transformations that have led to the segmentation and diversification of its market, reductions in the life cycle of vehicle models, and the offer of a variety of features of these models to consumers. Within this context, this paper analyzes these trends and evaluates the key strategies developed and implemented by Brazilian and European automakers in face of these trends. Our findings, which are analyzed using the same methodology adopted in a similar survey conducted in Europe, indicate how platform, late configuration and option bundling strategies have been implemented by automakers, allowing for a comparison of the two markets in question.
\end{abstract}

Keywords: automotive industry, variety, platforms, modularization, late configuration. 